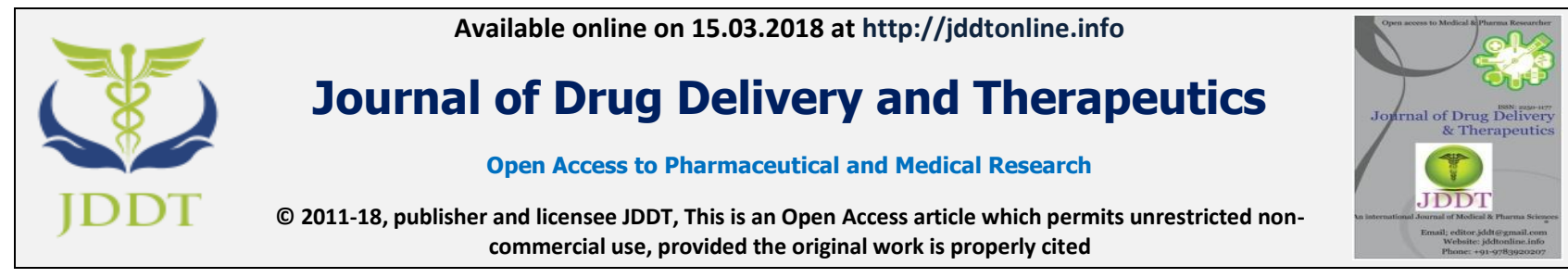

Open $\odot$ Access

Research Article

\title{
IMPROVED DISSOLUTION CHARACTERISTICS AND SOLUBILITY ENHANCEMENT OF POORLY WATER SOLUBLE DRUG BY NOVEL METHOD USING NATURAL GUM AND WATER SOLUBLE POLYMER
}

\author{
Taranjit Kaur*1, Prachi Sharma ${ }^{2}$ \\ ${ }^{1}$ Department of Pharmaceutics, ASBASJSMCOP, Bela Ropar, Punjab, India \\ ${ }^{2}$ St. Soldier College of Pharmacy, Jalandhar, Punjab, India
}

\begin{abstract}
The main objective of the present study is too prepared, characterized and evaluate and surfactant used as a carrier in solid dispersions for enhancing the dissolution rate of simvastatin. The feasibility of formulating solid dispersions of pure drug with gum and surfactant combination that enhanced dissolution rate was also investigated. Solid dispersions of simvastatin in gum: surfactant different polymer ratios were prepared by kneading method and evaluated for dissolution rate and efficiency. All the solid dispersions prepared gave rapid and higher dissolution of simvastatin when compared with pure drug. The DE60 was also increased from many folds in the case of pure drug and solid dispersions. Experimental design was applied systematically and determine the influence of the individual and combined effect on independent variables (X1) ratio and (X2) concentration of surfactants on the dependent variables percent dissolution efficiency at $60 \mathrm{~min}$ (\%DE 60) and yield percent and optimized formulation selected and characterised by its UV, Differential scanning caloriemetery, Scanning electron microscopy and X- Diffraction studies and formulated into capsule dosage form. In conclusion, the result of this work to suggest that solid dispersion is a useful technique for enhancing the solubility and dissolution study of water insoluble drug.
\end{abstract}

Keywords: Solubility enhancement, Poorly water soluble drug, Simvastatin, Solid dispersions

Article Info: Received 09 Jan, 2018; Review Completed 27 Feb, 2018; Accepted 01 March, 2018; Available online 15 March, 2018

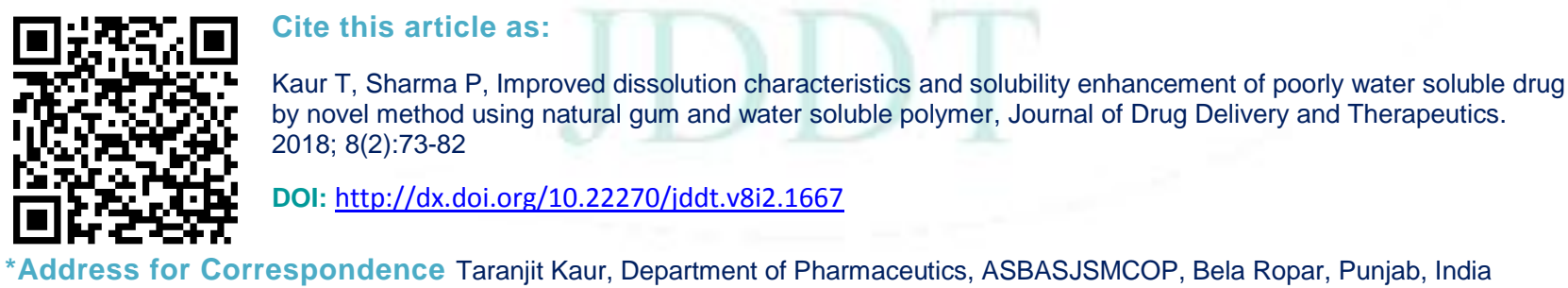

\section{INTRODUCTION}

Today most challenging and important aspects in the pharma industries are related with strategies that improved and enhanced the solubility of poorly soluble drugs. Low solubility and dissolution rate of water insoluble drugs in the aqueous gastrointestinal fluids and cause insufficient bioavailability and especially for Class II category according to the Biopharmaceutics Classification System (BCS), the bioavailability may be enhanced by increasing the solubility and dissolution rate of the drug in the gastro-intestinal fluids. ${ }^{1}$ The production of solid dispersions (SDs) is one of the acknowledged methods and used to enhance the aqueous solubility, thereby increasing the oral bioavailability and dissolution rate of drugs with aqueous low solubility ${ }^{2,3}$. Greater stability, easy production, accurate dosage form and patient's perspective are the main reasons behind the preference of solid oral dosage form. Solid dispersions are one of the most successful strategies to improve the drug release profile of the water insoluble drugs $^{4,5}$. Simvastatin is a 2,2-Dimethylbutanoic acid $(1 S, 3 R, 7 S, 8 S, 8 \mathrm{a} R)-1,2,3,7,8,8$ ahexahydro-3,7-

dimethyl-8-[2-[(2R,4R)-tetrahydro-4 hydroxy-6-oxo2Hpyran-2yl]ethyl]-1-naphthalenyl ester (BCS Class II) and cholesterol lowering agent and synthetically obtained from Aspergills terreus. It is a potent inhibitor of 3-hydroxy-3-methyl-glutaryl-coenzyme A (HMG-Co A) Reductase which catalyzes the conversion of HMGCo A to mevalonate and inactive lactone is rapidly 
metabolized to its corresponding beta-hydroxy acid (Simvastatin acid, SVA) after oral administration 6, 7 . Locust Bean Gum (LBG) (Carob Gum) is mainly consisting of the high molecular weight (approximately50,000-3,000,000)polysaccharides composed of galactomannans and obtained from the refined endosperm of seeds from the carobtree Ceretonia Siliqua and evergreen tree of the legume family and a white to yellowish white, nearly odourless powder and insoluble in most organic solvents. ${ }^{8,9}$ The Poloxamer polyols as a series of closely related block copolymers of ethylene oxide and propylene oxide conforming to the general formula $\mathrm{O}$ $(\mathrm{C} 2 \mathrm{H} 4 \mathrm{O}) \mathrm{a}(\mathrm{C} 3 \mathrm{H} 6 \mathrm{O}) \mathrm{b}(\mathrm{C} 2 \mathrm{H} 4 \mathrm{O}) \mathrm{H}$ and group of block copolymer non-ionic surfactants and widely used as emulsifiers, solubilising agents, and suspension stabilizers in liquid, oral, topical, and parenteral dosage forms, wetting agents and plasticizers, and give better results for enhancing the solubility and dissolution of sparingly soluble drugs in solid dosage Poloxamer 188 (POL) is a non-ionic block copolymer chain and widely used for increasing the aqueous solubility of poorly water-soluble drugs and thus selected as a carrier for dissolution enhancement of a poorly water-soluble drug. ${ }^{10,11}$

\section{MATERIAL AND METHODS}

\section{Material}

The pure drug gift sample simvastatin received from Dr. Reddys' Pharmaceuticals' Ltd. Hyderabad. The hydrophilic surfactant Poloxamer 188 received as a gift sample from Sigma Aldrich Chem P Ltd. Mumbai and other chemicals i.e. ethanol, methanol, magnesium state, talc, lactose, disodium hydrogen orthophosphate and potassium dihydrogen orthophosphate were purchased from Loba Chemicals Mumbai, India.

\section{Methods}

\section{Characterisation Parameters of pure drug}

The pure drug sample was analysed by different means such as colour, odour and texture in order to prove the authenticity of the sample.

\section{Solubility Determination of pure drug sample by UV spectroscopy}

\section{Absorption maxima of pure drug $\left(\lambda_{\max }\right)$}

The pure drug sample was determined in different solvents by preparing the $10 \mu \mathrm{g} / \mathrm{ml}$ solution of the drug and its absorption maxima was scanned by UV spectrophotometer between 200nm-400nm.

\section{Preparation of Standard Plot in Distilled water}

Pure drug sample $(50 \mathrm{mg})$ was dissolved in small amount of methanol (used as cosolvent), and diluted to $100 \mathrm{ml}$ of distilled water. $50 \mathrm{ml}$ of this solution was taken and diluted to $100 \mathrm{ml}$ with distilled water to prepare a stock solution of $250 \mu \mathrm{g} / \mathrm{ml}$ as a stock solution and prepared aliquots of $0.1 \mathrm{ml}, 0.2 \mathrm{ml}, 0.3 \mathrm{ml}, 0.4 \mathrm{ml}, 0.5 \mathrm{ml}, 0.6 \mathrm{ml}$ and $0.7 \mathrm{ml}$ and transferred to $10 \mathrm{ml}$ volumetric flask and volume was made up to $10 \mathrm{ml}$ with distilled water. The absorbance of these solutions was measured at $239 \mathrm{~nm}$ using distilled water as blank.

\section{Characterisation parameters of LBG/MLBG ${ }^{12}$}

\section{Viscosity measurement}

The viscous nature of locust bean gum and modified locust bean gum was measured at $37 \pm 1^{\circ} \mathrm{C}$ by using searle type viscometer, DV-E- Brookfield Viscometer, with spindle number 62 at $10 \mathrm{rpm}$.

\section{Angle of repose}

The accurately weighed powder was taken in a funnel and height of a funnel was adjusted in such a way and its tip just touches the apex of the heap of powder and allowed to flow through funnel freely onto the surface. The diameter of the powder heap was measured and angle of repose was calculated by using the following equation:

$\tan (\theta)=\mathrm{h} / \mathrm{r}$

Eq. 1

$\mathrm{h}$ Height of powder heap and $\mathrm{r}$ Radius of powder heap

\section{Density}

The loose bulk density (LBD) and tapped bulk density (TBD) of LBG/MLBG powder were determined. Powdered gum (2 gm) was poured into calibrated measuring cylinder (10 ml capacity) and noted initial volume and cylinder was allowed to fall under its own weight onto the hard surface from the height of $2.5 \mathrm{~cm}$. The tapping was then continued until no further change in volume was noted. LBD and TBD were calculated using the following equation:

$\mathrm{LBD}=\mathrm{Wt}$ of the powder/Volume of the packing

$\mathrm{TBD}=\mathrm{Wt}$ of the powder/Tapped volume of the packing Eq 3

\section{Phase Solubility Studies}

Solubility measurements were performed in which excess amount of pure drug $(20 \mathrm{mg})$ was added in $20 \mathrm{ml}$ of distilled water containing increasing concentrations of the MLBG (i.e. $0.25 \%, 0.5 \%, 1 \%, 1.25 \%, 1.5 \%$, and $2 \%$ ) in screw capped vials, sealed and shaken at room temperature for $48 \mathrm{~h}$ on a water bath shaker and the samples were filtered and analysed spectrophometrically at $239 \mathrm{~nm}$.

\section{Kneading method}

Accurately weighed pure drug and MLBG in drug: polymer ratio of 1:2, 1:5, and 1:8 for 5 min using glass mortar and pestle and physical mixture was triturated by using a small volume of ethanol-water solution and form a thick paste and kneaded for 30 min respectively, dried at $45^{\circ} \mathrm{C}$ in an oven. The dried mass was pulverized and passed through 60 mesh sieve size, weighed and transferred to airtight container and stored for further use ${ }^{13,14}$

\section{Characterisation of Solid dispersions}

Determination of percentage yield and drug content ${ }^{15}$

\section{Drug content}

Pure drug and solid dispersions equivalent to $10 \mathrm{mg}$ dissolved in a suitable amount of methanol $(25 \mathrm{ml})$, filtered, suitably diluted with methanol and drug content was analyzed by UV spectrophotometer. 


\section{Percentage yield}

The percentage yield of the solid dispersions and the total weight of drug and carrier used and calculated by following equation:

$$
\% \text { Yield }=(\mathrm{a} / \mathrm{b}+\mathrm{c}) * 100 \quad \text { Eq. } 4
$$

Whereas, a: the weight of the solid dispersion sifted and b: the weight of simvastatin taken for solid dispersion preparation c: the weight of the MLBG and the wei4wght of surfactant.

\section{Determination of solubility of solid dispersions}

Simvastatin and different solid dispersions equivalent to $10 \mathrm{mg}$ were weighed and added in $10 \mathrm{ml}$ of Phosphate buffer $\mathrm{pH} 6.8$ in screw capped vials and capped tightly, vortexed for $2 \mathrm{~min}$ and shaken at $37 \pm 2^{\circ} \mathrm{C}$ in a temperature controlled water bath for $24 \mathrm{hrs}$. Resultant samples containing un-dissolved solid dispersions suspended in the screw capped vials were centrifuged and filtered, suitably diluted with phosphate buffer $\mathrm{pH}$ 6.8 and analyzed by UV spectrophotometer at $239.5 \mathrm{~nm}$.

\section{In-vitro drug release studies ${ }^{15}$}

Dissolution studies were conducted by using USP XXIV paddle method (apparatus 2) official in USP and Pure drug and solid dispersions equivalent to $10 \mathrm{mg}$ of simvastatin was added in $900 \mathrm{ml}$ phosphate buffer $\mathrm{pH} 6.8$ at speed of $100 \mathrm{rpm}$ at temperature of $37 \pm 0.5^{\circ} \mathrm{C}$ and pipette out $10 \mathrm{ml}$ solution was collected periodically and replaced with $10 \mathrm{ml}$ of freshly prepared dissolution medium and collected samples were analysed at $239.5 \mathrm{~nm}$ by using UV-visible spectrophotometer against phosphate buffer pH6.8 used as blank.

\section{Experimental Design}

The various type of designs available for the optimization of dosage form and full factorial design was selected with its systematically study that effect upon the influence of the individual and combined effect of independent variables ratio $\left(\mathrm{X}_{1}\right)$ and concentration of surfactants $\left(\mathrm{X}_{2}\right)$ on the dependent variables percent dissolution efficiency at $60 \mathrm{~min}\left(\% \mathrm{DE}_{60}\right)$ and percent yield. In this design, two factors are evaluated each at three levels and experimental trials were performed at all nine possible combinations and statistical model incorporating interactive and polynomial terms is used to evaluate the response ${ }^{16}$.

$\mathrm{Y}=\mathrm{b}_{0}+\mathrm{b}_{1} \mathrm{X}_{1}+\mathrm{b}_{2} \mathrm{X}_{2}+\mathrm{b}_{12} \mathrm{X}_{1} \mathrm{X}_{2}+\mathrm{b}_{11}\left(\mathrm{X}_{1}\right)^{2}+\mathrm{b}_{22}\left(\mathrm{X}_{2}\right)^{2} \quad$ Eq. 5

Where, $\mathrm{Y}$ is the dependent variable, $\mathrm{b}_{0}$ is the arithmetic mean response of the nine runs, and $b_{1}$ is the estimated coefficient for the factor $X_{1}$ and main effects $\left(X_{1}\right.$ and $\mathrm{X}_{2}$ ) represent the average result of changing one factor at a time from its low to high value and interaction terms $\left(\mathrm{X}_{1} \mathrm{X}_{2}\right)$ show the responsive changes when two factors are simultaneously changed. The polynomial terms $\left(\left(\mathrm{X}_{1}\right)^{2}\right.$ and $\left.\left(\mathrm{X}_{2}\right)^{2}\right)$ were included to investigate nonlinearity.

Table 1: Composition of factorial batches using Poloxamer 188

\begin{tabular}{|c|c|c|}
\hline \multicolumn{3}{|c|}{ Variables levels in coded } \\
\hline $\begin{array}{c}\text { Batch } \\
\text { code }\end{array}$ & $\begin{array}{c}\mathbf{X}_{\mathbf{1}} \\
\text { (Ratio) }\end{array}$ & $\begin{array}{c}\mathbf{X}_{\mathbf{2}} \\
\text { (Concentration) }\end{array}$ \\
\hline SIM 22 & -1 & -1 \\
\hline SIM 25 & -1 & 0 \\
\hline SIM 28 & -1 & +1 \\
\hline SIM 23 & 0 & -1 \\
\hline SIM 26 & 0 & 0 \\
\hline SIM 29 & 0 & +1 \\
\hline SIM 24 & +1 & -1 \\
\hline 'SIM 27 & +1 & 0 \\
\hline SIM 30 & +1 & +1 \\
\hline Coded values & Actual values & Concentration of surfactant \\
& & Poloxamer 188 ( \% w/w) \\
\hline-1 & $1: 2$ & 4 \\
\hline 0 & $1: 5$ & 8 \\
\hline+1 & $1: 8$ & 12 \\
\hline
\end{tabular}

\section{Characterization of Optimized Solid Dispersions}

\section{Differential scanning calorimetry}

Thermal analyses were performed on the sample of pure drug and optimized solid dispersions were placed in a sealed aluminium pan and heated at a scanning rate of $30^{\circ} \mathrm{C} / \mathrm{min}$ from $25^{\circ} \mathrm{C}$ to $200^{\circ} \mathrm{C}$ temperature range.

Fourier transform infrared spectroscopy
Fourier transform infrared (FT-IR) spectroscopy was employed to characterize the possible interactions between the drug and the carrier in the solid state on an FT-IR spectrophotometer by the conventional $\mathrm{KBr}$ pellet method.

\section{Powder x-ray diffraction analysis (XRD)}

Powder XRD patterns of pure drug and optimized solid dispersion were recorded using diffractometer Philips 
PW 1729 X-ray generator under the following conditions: target $\mathrm{CuKa}$ monochromatized radiations, voltage $40 \mathrm{KV}$, and current $40 \mathrm{~mA}$ at ambient temperature.

\section{Scanning electron microscopy (SEM)}

The scanning electron microscopy (SEM) analysis was carried out on the samples of pure drug and the optimized solid dispersions were mounted onto the stubs using double-sided adhesive tape and then coated with a thin layer of gold palladium alloy $\left(150-200 \mathrm{~A}^{\circ}\right)$.

\section{Formulation of Optimized Batch into Capsules Dosage Form}

The optimized solid dispersions were prepared by using the excipients as lactose were co-grinded in pestle and motor (except talc and magnesium stearate) and passed through mesh no. 60 and then added talc and magnesium stearate and mixed for 5 minutes and prepared hard gelatin capsules.

\section{Evaluation Parameters of Capsules ${ }^{7}$}

\section{General appearance}

The general appearance of a capsule shell, its visual identification and over all 'elegance' is essential.

\section{Weight variation test}

The weight variation test was performed on weighing the intact the capsules individually and the average weight is determined. The tests requirements were met if none of the individual weighs are less than $90 \%$ or more than $110 \%$ of the average. If the original 20 did not meet these criteria, the individual net weighs are determined. These were averaged and differences were determined between individual net content and the average.

\section{Disintegration test}

In vitro disintegration time was determined using disintegration test apparatus. If the capsule floats on to the surface of the medium, a disc may be added. If the capsules adhere to the discs, attach a removable piece of stainless steel woven gauze with mesh apparatus of $2.00 \mathrm{~mm}$ to the upper plate of the basket rack assembly and carry out the test omitting the discs. In this case, each capsule was placed in each of six tubes of apparatus and a disc was added to each tube that is three inches long, open at the top, and held against a 10 mesh screen at the bottom end of the basket rack assembly. The basket rack assembly was positioned in a one litre of distilled water at $37^{\circ} \mathrm{C} \pm 20^{\circ} \mathrm{C}$. The time taken for the capsule to disintegrate completely and pass through the screen was measured. Operate the apparatus for 30min unless otherwise directed.

\section{Content uniformity}

The content uniformity was performed by specified individual monographs. The requirements are met for the capsules if 9 of the 10 are specified potency range of 85 to $115 \%$ and tenth not outside 75 to $125 \%$.

\section{In vitro dissolution test}

The dissolution studies were performed on the formulated capsule dosage forms in phosphate buffer $\mathrm{pH}$
6.8. by using rotating paddle method and equivalent to $10 \mathrm{mg}$ of pure drug and capsule dosage form was added to $900 \mathrm{ml}$ of phosphate buffer $\mathrm{pH} 6.8$ (100rpm at $37 \pm 0.5^{\circ} \mathrm{C}$ ) and $10 \mathrm{ml}$ of aliquots were withdrawn at different time intervals and immediately filtered and replaced with $10 \mathrm{ml}$ of freshly prepared dissolution medium. The concentration of SIM was measured spectrophotometrically at $239.5 \mathrm{~nm}$ and $\left(\% \mathrm{DE}_{60}\right) \& \%$ drug released of the capsules was determined and compared with the pure drug.

\section{Stability studies}

Accelerated stability studies were performed on prepared solid dispersion capsule dosage form in amber coloured screw capped bottles and were checked as per $\mathrm{ICH}$ guidelines at $40 \pm 2^{\circ} \mathrm{C}$ and $75 \pm 5 \% \mathrm{RH}$ up to one month. The capsules were kept in stability chamber. Samples were removed at regular intervals as initial, 7 days, 14 days, 21 days and 30 days and were analyzed for physical characterization, content uniformity and in vitro dissolution studies. The similarity factor (f2) was used as a basis to compare dissolution profiles. The dissolution profiles are considered to be similar when $\mathrm{f} 2$ is between 50 and100 and calculated by the given formula:

$$
f_{2}=50 \log \left\{\left[1+(1 / n) \sum_{t=1}{ }^{n}\left(R_{t}-T_{t}\right)^{2}\right]^{-0.5} 100\right\}
$$

Eq. 6

Where, $\mathrm{n}$ is the dissolution time and $\mathrm{Rj}$ and $\mathrm{Tj}$ are the reference and test dissolution values at time $t$. (Morre Flamer equation).

\section{Physiochemical Characterisation of Pure Drug}

The sample of pure drug was characterised by its color, odor, taste and texture as given in officials (Indian pharmacopoeia). Similarly, It is white in color and crystalline nature and its melting point was $138.0^{\circ} \mathrm{C}$ determined by Capillary method which is similar with literature value.

\section{Maximum Absorption of Wavelength of Pure Drug}

The maximum absorption wavelength of pure drug was observed in distilled water as shown in the given fig 1 .

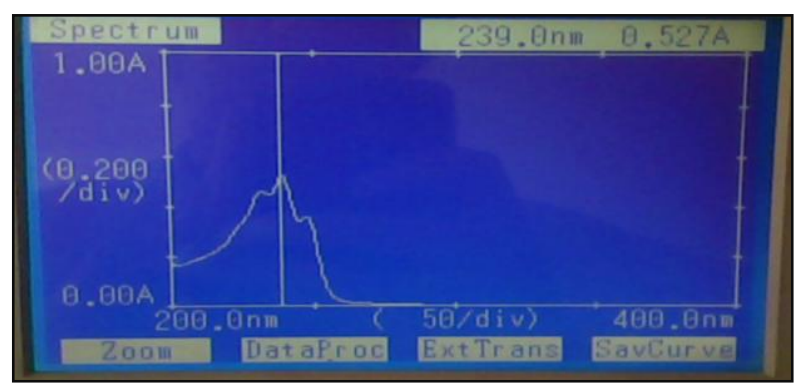

Figure 1: Scan graph of Simvastatin in Distilled water

\section{Preparation of Standard Plot in Distilled water}

The calibration plot of various concentrations of drug was found to be linear concentration range of 2.5 to $15 \mu \mathrm{g} / \mathrm{ml}$ at $239.0 \mathrm{~nm}$ in distilled water as shown in the Fig. 2. 


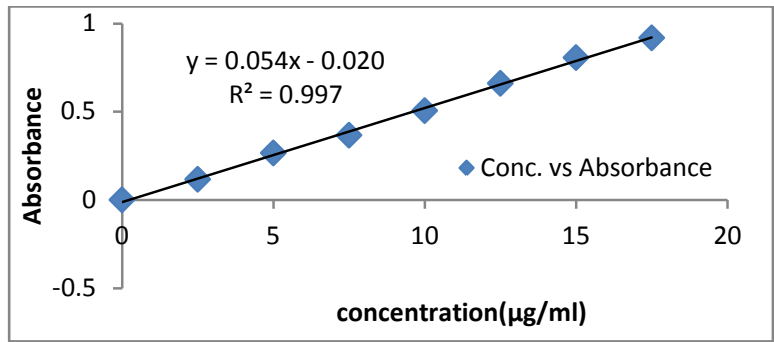

Figure 2: Standard curve of Simvastatin in distilled water

\section{RESULTS AND DISCUSSION}

\section{Characterisation parameters of LBG/MLBG}

The characterised parameters of gum was determined by its viscosity, angle of repose and density parameters and excessive heating was performed in hot air oven and reduces its value that forms modified locust bean gum as shown in the given Table no.2.

\begin{tabular}{|c|c|c|}
\hline Parameters & LBG & MLBG \\
\hline Viscosity(cps) & $1661 \pm 2.1$ & $581 \pm 2.6$ \\
\hline Angle of repose & $38.836 \pm 0.45$ & $37.736 \pm 0.19$ \\
\hline Carrs index $(\%)$ & $21.6 \pm .27$ & $19.2 \pm .57$ \\
\hline
\end{tabular}

Table 2: Characterisation parameters of LBG/MLBG

Data are expressed as mean \pm S.D. $(n=3)$

\section{Phase solubility studies}

The solubility profile of pure drug was determined by plotting the graph between the solubility of drug against concentration of polymer (\%) in aqueous solution and type of solubility diagram, which shows the linear increase in the solubility of drug with increased concentration of carrier $\mathrm{R}^{2}$ value of 0.999 and giving an $A_{L}$ type solubility diagram (23). Solubility data of Simvastatin in different concentration of modified locust bean gum as shown in the shown in Fig 3.

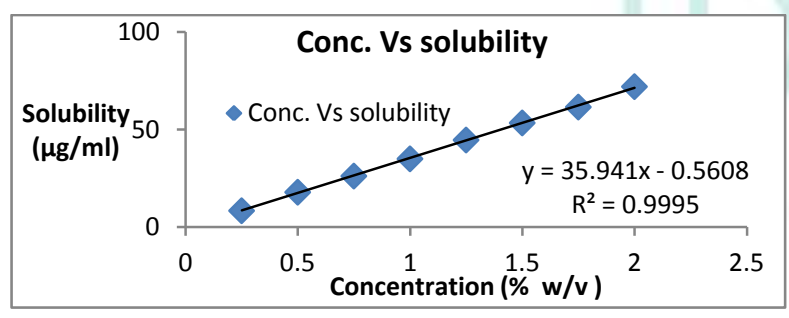

Figure 3: Effect of increasing concentration of MLBG on solubility of pure drug

Characterisation of Solid dispersions

\section{Determination of percentage yield and drug content}

The drug content of the pure drug and solid dispersions was determined as 98.22-97.01\% \pm 0.01 and \% Yield of prepared solid dispersions determined as increased from 72.6-83.2 $\pm 0.24 \%$ and decreased at higher concentration ratios cause difficult in sieving due to higher polymersurfactants ratios and deviate values of standard deviation in percent yield.

\section{Determination of solubility of solid dispersions}

Solubility data of pure drug and different solid dispersions as shown in given Table 3.
Table 3: Solubility data of different solid dispersions with Poloxamer188

\begin{tabular}{|c|c|}
\hline Formulation codes & Solubility $(\boldsymbol{\mu}$ g/ml $)$ \\
\hline \multicolumn{2}{|c|}{ Poloxamer 188 (4 \% w/w) } \\
\hline SIM 22 & $9.52 \pm 0.00$ \\
\hline SIM 23 & $20.08 \pm 0.00$ \\
\hline SIM 24 & $43.67 \pm 0.63$ \\
\hline \multicolumn{2}{|c|}{ Poloxamer 188 (8 \% w/w) } \\
\hline SIM 25 & $12.55 \pm 0.00$ \\
\hline SIM 26 & $27.31 \pm 0.29$ \\
\hline SIM 27 & $48.78 \pm 0.24$ \\
\hline \multicolumn{2}{|c|}{ Poloxamer 188 (12 \% w/w) } \\
\hline SIM 28 & $18.58 \pm 0.00$ \\
\hline SIM 29 & $42.87 \pm 0.56$ \\
\hline SIM 30 & $53.48 \pm 0.46$ \\
\hline Data are expressed as mean \pm S.D. $(\mathrm{n}=3)$
\end{tabular}

\section{In-vitro drug release studies}

The In-vitro release of pure drug and different solid dispersions were determined as shown in Table 6. and plotted the graph between $\%$ drug released vs. time as shown below from Fig. $4-6$ respectively.

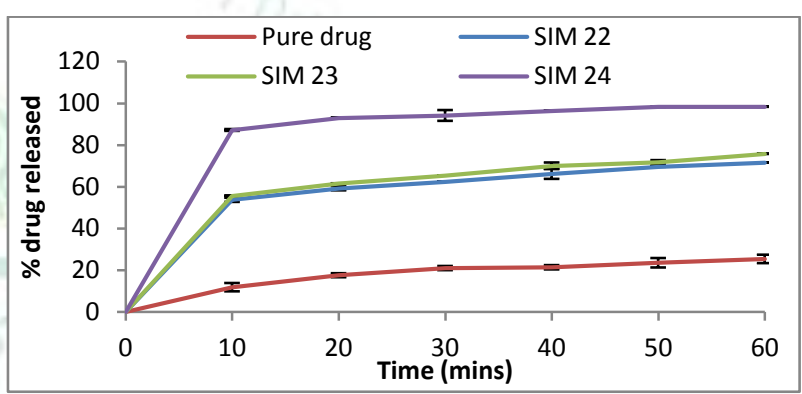

Figure 4: In-vitro dissolution profile of \%pure drug released vs. time solid dispersions with Poloxamer 188(4\%)

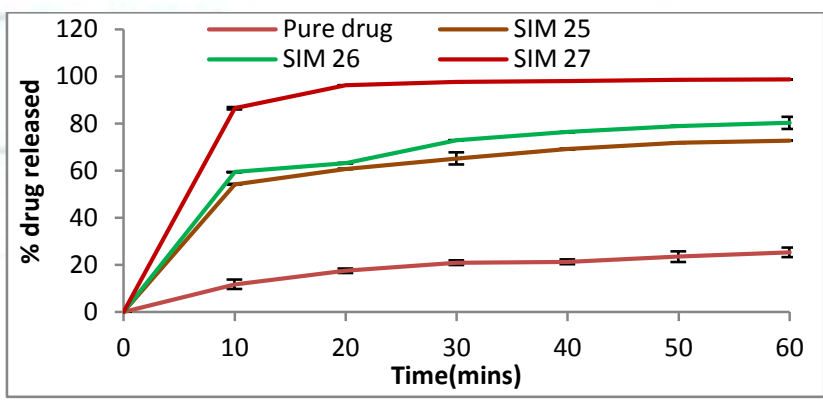

Figure 5 In-vitro dissolution profile of \%pure drug released vs. time solid dispersions with Poloxamer 188 (8\%)

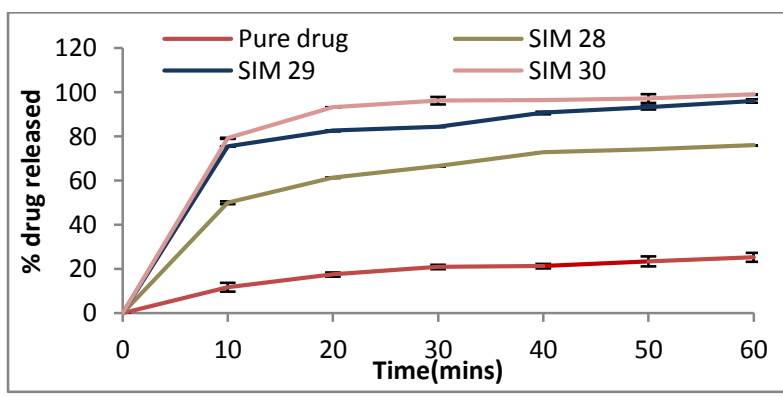

Figure 6: In-vitro dissolution profile of \%pure drug released vs. time solid dispersions with Poloxamer $188(12 \%)$ 


\section{Experimental Design}

The experimental designs were applied on the above prepared solid dispersions which is shown as below:

Table 4: Composition of Factorial Design Batches with Poloxamer 188

\begin{tabular}{|c|c|c|c|c|}
\hline \multicolumn{5}{|c|}{ Variables levels in coded } \\
\hline Batch code & $\begin{array}{c}\mathbf{X}_{\mathbf{1}} \\
\text { (Ratio) }\end{array}$ & $\begin{array}{c}\mathbf{X}_{\mathbf{2}} \\
\text { (Concentration) }\end{array}$ & $\mathbf{\%}_{\mathbf{6 0}} \mathbf{\pm S D}$ & \% Yield \pm SD \\
\hline SIM 22 & -1 & -1 & $57.81 \pm 0.143$ & $72.5 \pm 0.24$ \\
\hline SIM 25 & -1 & 0 & $59.58 \pm 0.723$ & $73.5 \pm 0.10$ \\
\hline SIM 28 & -1 & +1 & $61.42 \pm 1.091$ & $74.8 \pm 0.25$ \\
\hline SIM 23 & 0 & -1 & $60.32 \pm 0.317$ & $80.5 \pm 0.11$ \\
\hline SIM 26 & 0 & 0 & $65.17 \pm 0.063$ & $81.9 \pm 0.22$ \\
\hline SIM 29 & 0 & +1 & $73.3 \pm 0.143$ & $82.9 \pm 0.03$ \\
\hline SIM 24 & +1 & -1 & $86.51 \pm 0.874$ & $81.5 \pm 0.32$ \\
\hline SIM 27 & +1 & 0 & $89.12 \pm 1.215$ & $80.3 \pm 0.47$ \\
\hline SIM 30 & +1 & +1 & $95.30 \pm 0.913$ & $80.0 \pm 0.39$ \\
\hline Coded values & Actual values & Concentration of surfactants & & \\
\hline & Poloxamer $\mathbf{1 8 8}(\mathbf{\%}$ w/w) & & \\
\hline
\end{tabular}

$\mathrm{X}_{1}$ drug to polymer ratio, $\mathrm{X}_{2}$ concentration of surfactants Poloxamer $188 \% \mathrm{DE}_{60}$ dissolution efficiency at $60 \mathrm{~min}$.
The regression analysis results ( $\mathrm{p}$ value) of the variables on percentage dissolution efficiency at $60 \mathrm{~min}$ and percent of yield of solid dispersion are shown in Table 5.

Table 5: Result of Regression Analysis

\begin{tabular}{|c|c|c|c|c|c|c|c|}
\hline \multicolumn{7}{|c|}{ Coefficients estimates } \\
\hline Response & $\mathbf{b}_{\mathbf{0}}$ & $\mathbf{b}_{\mathbf{1}}$ & $\mathbf{b}_{\mathbf{2}}$ & $\mathbf{b}_{\mathbf{1 2}}$ & $\mathbf{b}_{\mathbf{1 1}}$ & $\mathbf{b}_{\mathbf{2 2}}$ & $\mathbf{R}^{\mathbf{2}}$ \\
\hline \% DE $_{\mathbf{6 0}}$ & 65.49 & 15.35 & 4.23 & 1.29 & 8.69 & 1.15 & 0.9902 \\
\hline p value & - & 0.0005 & 0.00217 & 0.3351 & 0.0136 & 0.5377 & - \\
\hline \% yield & 81.68 & 3.50 & 0.53 & -0.95 & -4.67 & 0.13 & \\
\hline p value & - & 0.0012 & 0.1593 & 0.0732 & 0.0025 & 0.8054 & - \\
\hline
\end{tabular}

The ANOVA results of solid dispersions are shown in Table 6. According to $\mathrm{p}$ value, full model or reduced model can be selected, so in the present study, full model having both significant and non significant $\mathrm{p}$ values was used in obtaining dependent variables because the fitness of full model to the system is better than reduced model.

Table 6: The Results of Analysis of Variance

\begin{tabular}{|c|l|c|c|c|c|c|}
\hline Response & & df & SS & MS & F & $\mathbf{R}^{\mathbf{2}}$ \\
\hline \multirow{2}{*}{ DEE $_{\mathbf{6 0}}$} & Regression & 5 & 1682.22 & 336.44 & 60.87 & 0.9902 \\
\cline { 3 - 7 } & Error & 3 & 16.58 & 5.53 & - & - \\
\hline \multirow{2}{*}{\begin{tabular}{l} 
yield \\
\cline { 3 - 7 }
\end{tabular}} & Regression & 5 & 122.41 & 24.48 & 49.81 & 0.9881 \\
\cline { 3 - 7 } & Error & 3 & 1.47 & 0.49 & - & - \\
\hline
\end{tabular}

The equation can be generated by putting values of coefficients in following equation in terms of coded factors.

\section{Dissolution efficiency}

$\mathrm{Y}=\mathrm{b}_{0}+\mathrm{b}_{1} \mathrm{X}_{1}+\mathrm{b}_{2} \mathrm{X}_{2}+\mathrm{b}_{12} \mathrm{X}_{1} \mathrm{X}_{2}+\mathrm{b}_{11}\left(\mathrm{X}_{1}\right)^{2}+\mathrm{b}_{22}\left(\mathrm{X}_{2}\right)^{2}$

$\mathrm{Y}=64.59+15.35 \mathrm{X}_{1}+4.23 \mathrm{X}_{2}+1.29 \mathrm{X}_{1} \mathrm{X}_{2}+8.69\left(\mathrm{X}_{1}\right)^{2}+1.15$

$\left(\mathrm{X}_{2}\right)^{2}$

$\%$ Yield
$\mathrm{Y}=\mathrm{b}_{0}+\mathrm{b}_{1} \mathrm{X}_{1}+\mathrm{b}_{2} \mathrm{X}_{2}+\mathrm{b}_{12} \mathrm{X}_{1} \mathrm{X}_{2}+\mathrm{b}_{11}\left(\mathrm{X}_{1}\right)^{2}+\mathrm{b}_{22}\left(\mathrm{X}_{2}\right)^{2}$

$\mathrm{Y}=81.68+3.50 \mathrm{X}_{1}+0.53 \mathrm{X}_{2}-0.95 \mathrm{X}_{1} \mathrm{X}_{2}-4.67\left(\mathrm{X}_{1}\right)^{2}+0.13\left(\mathrm{X}_{2}\right)^{2}$

Coefficients with one factor indicate the effect of that particular factor, while the coefficients with more than one factor and those with second-order terms represent the interaction between those factors and the quadratic nature of the phenomena, respectively. Positive sign of the term indicates positive (additive) effect, while negative sign indicates negative (antagonistic) effect of 
the factor on the response. It can be concluded from the equations that $\mathrm{X}_{1}$ (drug: polymer ratio) shows the larger positive effect than term $X_{2}$ (concentration of surfactant PXM 188) on percentage dissolution efficiency at 60min and yield percent. The quadratic terms of $X_{1}$ and $X_{2}$ also had effect on percentage dissolution efficiency at $60 \mathrm{~min}$ and yield percent. Fig.7 and 8 shows the contour plots and response surface plots for percentage dissolution efficiency.

The reliability of the equations that describes the influence of factors on percentage dissolution efficiency at $60 \mathrm{~min}$ and $\%$ yield was assessed by preparing two additional check points solid dispersions (batch PXM 1881 and PXM 188 2) in triplicate using the amount of $\mathrm{X}_{1}$ and $\mathrm{X}_{2}-1$ and +1 level. The experimental values and predicted values of each response are shown in Table 7. Equation was used to calculate percentage relative error between predicted values and experimental values of each response. The percentage relative error obtained from checkpoint batches was in the range of 1.2to 0.23. Low values of the relative error show that for both factors, there is a reasonable agreement of predicted values and experimental values. This proves the validity of model and confirms the effects of drug: polymer ratio and the concentration of surfactant PXM 188 on percentage dissolution efficiency at $60 \mathrm{~min}$ and yield percent.

$\%$ Relative error $=[($ Predicted value- experimental value)/predicted value ${ }^{*} 100 \quad$ Eq.6.1.

Table 7: Validation of Model Obtained Using Experimental and Predicted results of checking updates

\begin{tabular}{|l|c|c|c|c|c|c|l|c|}
\hline \multirow{2}{*}{ Batch code } & \multicolumn{2}{|c|}{ Variables } & $\begin{array}{c}\text { \%DE } \\
\text { Predicted }\end{array}$ & $\begin{array}{c}\text { \%DE 60 } \\
\mathbf{\pm S D} \\
\text { Exp }\end{array}$ & $\begin{array}{l}\text { \% Rel } \\
\text { error }\end{array}$ & $\begin{array}{c}\text { \% Yield } \\
\text { Predicted }\end{array}$ & $\begin{array}{l}\text { \% Yield } \\
\pm \text { SD } \\
\text { Exp. }\end{array}$ & $\begin{array}{l}\text { \%Rel } \\
\text { Error }\end{array}$ \\
\hline PXM 1881 & -1 & +1 & 62.92 & $63.71 \pm 2.6$ & 1.2 & 75.1 & $74.5 \pm 0.75$ & 0.79 \\
\hline PXM 188 2 & +1 & -1 & 85.16 & $84.17 \pm 0.51$ & 1.1 & 81.06 & $82.9 \pm 0.88$ & 0.23 \\
\hline
\end{tabular}

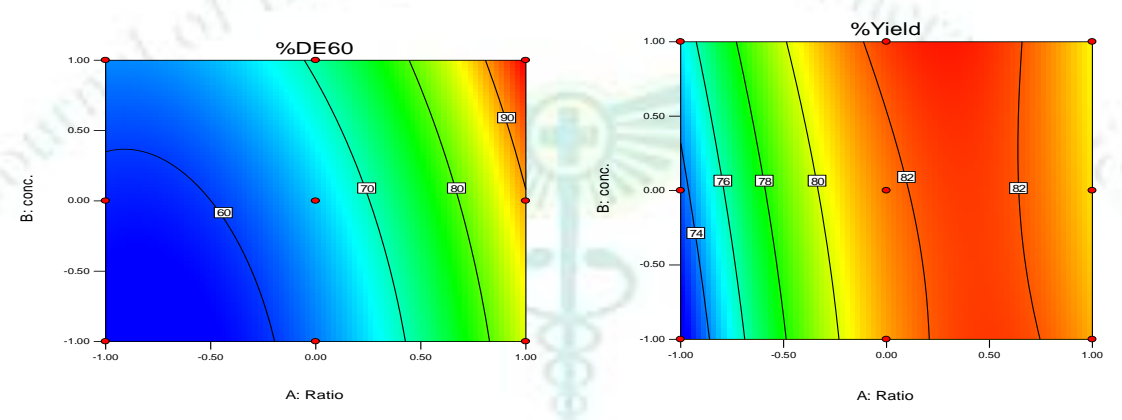

Figure 7: Contour plots with Poloxamer 188 showing a) Percentage dissolution efficiency at 60 min b) percentage yield.
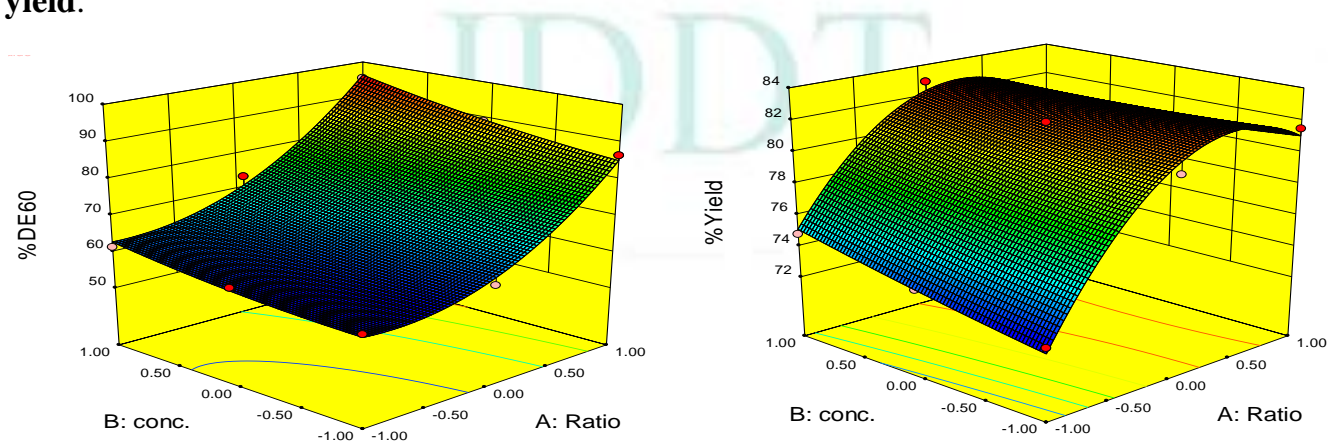

Figure 8: Response surface with Poloxamer 188 plots showing a) percentage dissolution efficiency at 60min b) Percentage yield.

The contour lines indicated that the higher the polymer and increasing the concentration of Poloxamer 188, the more significant in the dissolution enhancement. However, for yield percent, decrease at higher polymer ratio was observed, which may be attributed to difficulty of sieving when higher polymer ratio was used.

\section{Characterization of Optimized Solid Dispersions}

Differential scanning calorimetry
In the optimized preparation, due to higher polymer concentration ratio and uniform distribution of drug in the crust of polymer which indicates its miscibility of molten drug in polymer. Absence of sharp peak for the drug indicates that the drug is completely distributed homogenously in an amorphous nature state within the solid dispersions without any interaction as shown in the Fig. 9. 


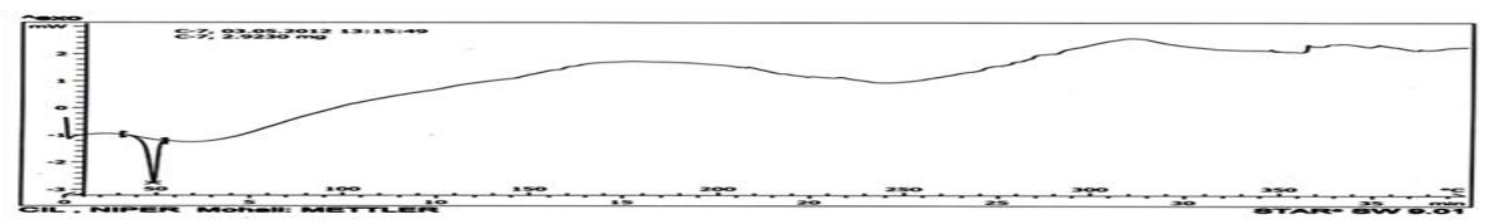

Figure 9: DSC Thermogram of optimized formulation with Poloxamer 188

\section{Fourier transform infrared spectroscopy}

Infrared spectra of pure drug, Poloxamer 188 and optimized solid dispersion as shown in the given figures and exhibited significant decrease in intensity of $\mathrm{O}-\mathrm{H}$ stretching vibrations which may be due to intermolecular hydrogen bonding in the optimized solid dispersions. The spectra peaks of drug were almost unchanged in the optimized solid dispersions which indicate that the overall symmetry of molecule was not affected.

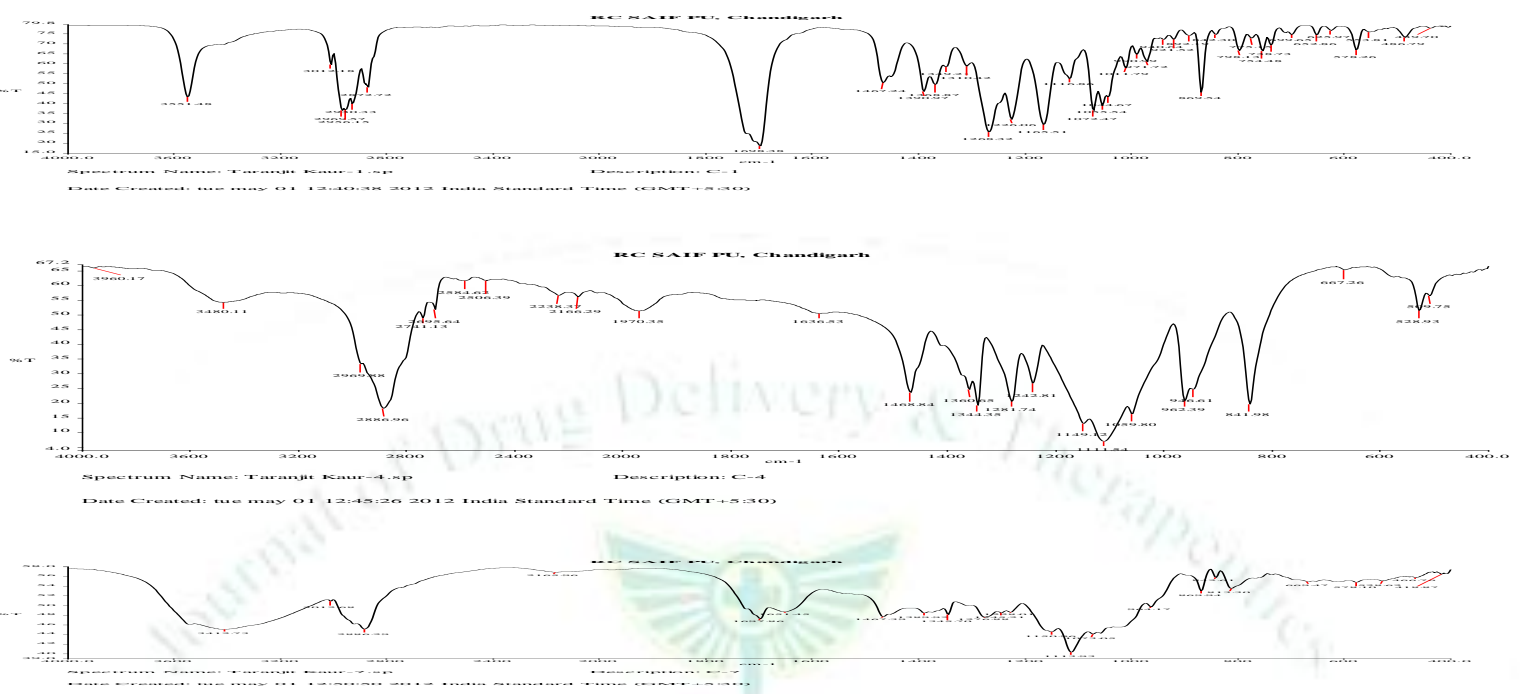

Figure 10: FTIR spectra of pure drug, Poloxamer 188 and optimised solid dispersion

\section{Powder x-ray diffraction analysis (XRD)}

The X-ray diffraction studies of Poloxamer 188 and optimized solid dispersions as shown in Fig. 11. Poloxamer 188 shows sharp peaks at $17^{\circ}, 19^{\circ}, 22^{\circ}$ when compared with that of simvastatin and shows with reduced peak height area were observed, this indicates the reduced in the crystallinity nature of the simvastatin as some of the drug converted into the amorphous form in the solid dispersions.
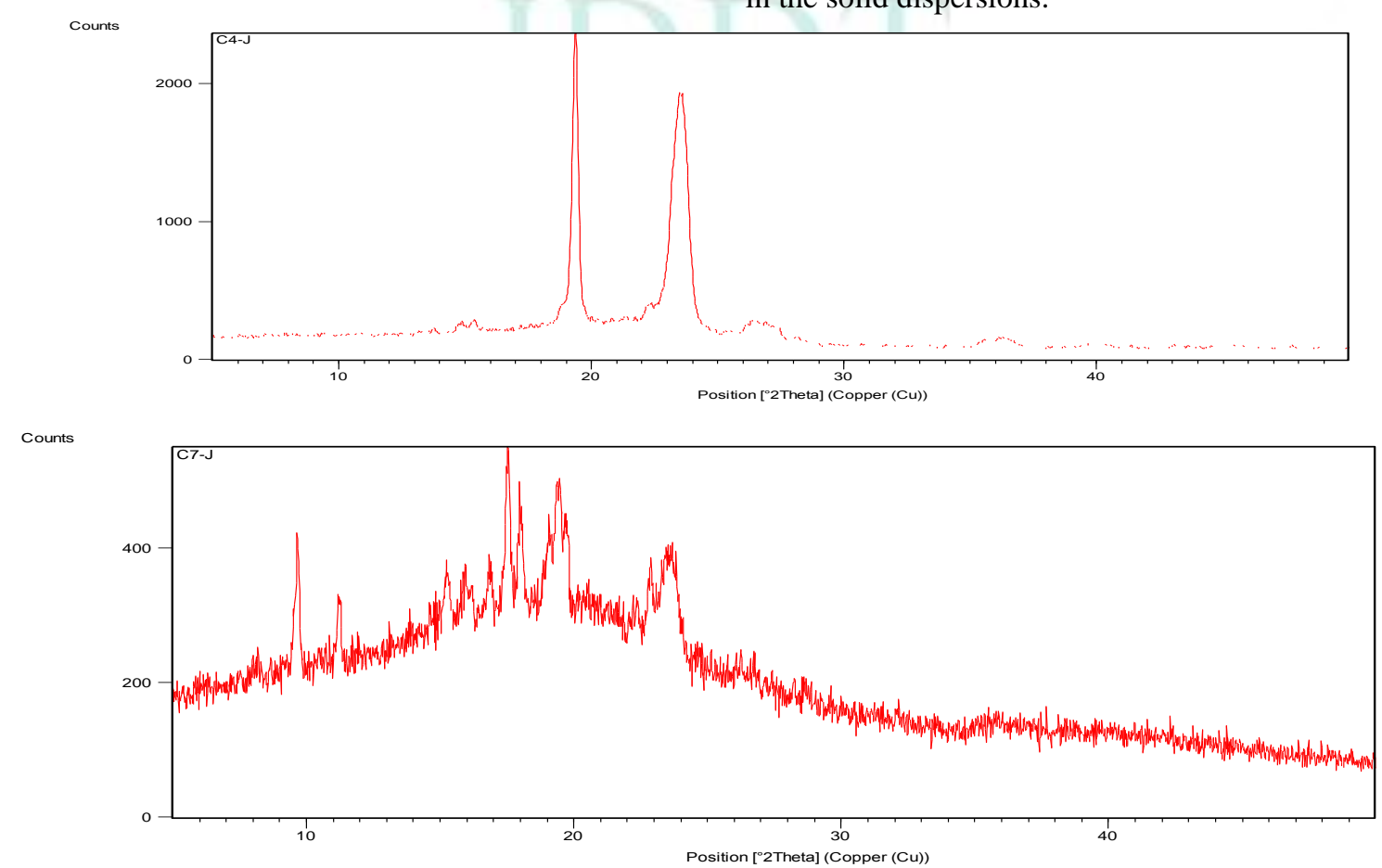

Figure 11: X-ray diffraction of ploxamer188 and optimized formulation 


\section{Scanning electron microscopy (SEM)}

Simvastatin was highly crystalline material and characterised by its needle shaped crystals and the crystals of solid dispersions of drug did not show any needle shaped crystals and shows uniform dispersion of the drug in the polymeric matrix of the polymer and surfactant was observed in the solid dispersions and that reduces the crystallinality nature of the drug and changes into an amorphous form as shown in the given Fig. 12.
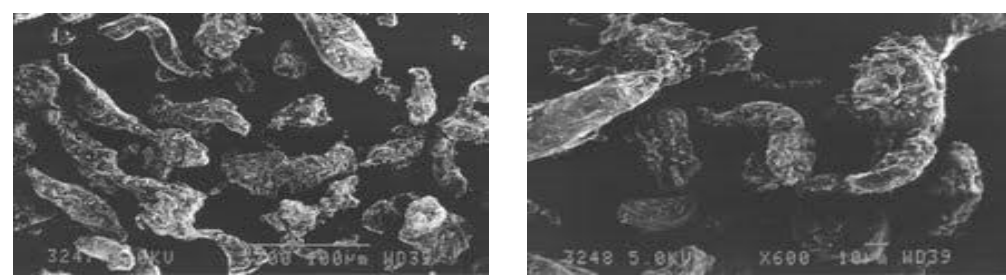

Figure 12: Scanning electron photomicrograph of optimized solid dispersion Poloxamer 188 at 300 and $600 \mathrm{X}$

The optimized solid dispersions were filled into hard gelatin capsule shell and the final capsule dosage forms by using lactose, talc and other excipients were prepared and designated as C3.

\section{Evaluation Parameters of Capsules}

Table 8: Evaluation parameters of Capsule dosage form C3 with Poloxamer 188

\begin{tabular}{|c|c|c|c|}
\hline Formulation code C3 & $\begin{array}{c}\text { Weight variation } \\
(\mathbf{m g})\end{array}$ & $\begin{array}{c}\text { Disintegration time } \\
(\mathbf{m i n})\end{array}$ & $\begin{array}{c}\text { Content uniformity } \\
(\mathbf{\%})\end{array}$ \\
\hline 1 & $238 \pm 0.001$ & 25 & $98.54 \pm 0.27$ \\
\hline 2 & $244 \pm 0.005$ & 26 & $96.93 \pm 0.05$ \\
\hline 3 & $241 \pm 0.125$ & 28 & $96.90 \pm 0.055$ \\
\hline 4 & $236 \pm 0.126$ & 31 & $97.03 \pm 0.05$ \\
\hline 5 & $239 \pm 0.458$ & 29 & $96.96 \pm 0.05$ \\
\hline 6 & $239 \pm 0.235$ & 31 & $97.58 \pm 0.03$ \\
\hline 7 & $236 \pm 0.259$ & 27 & $98.64 \pm 0.03$ \\
\hline 8 & $235 \pm 0.369$ & 30 & $97.71 \pm 0.05$ \\
\hline 9 & $233 \pm 0.258$ & 26 & $99.96 \pm 0.05$ \\
\hline 10 & $235 \pm 0.240$ & 28 & $98.22 \pm 0.06$ \\
\hline
\end{tabular}

Data are expressed as mean \pm S.D $(n=3)$

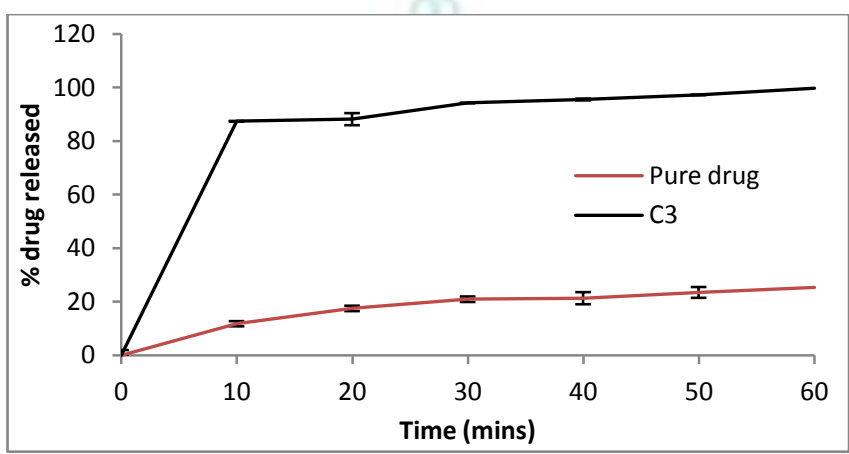

Figure 13: In vitro dissolution profile of \%drug released vs time of pure drug and Capsule dosage forms

\section{CONCLUSION}

Result was observed from the experimental design that significantly influences the dependent variables $\% \mathrm{DE}_{60}$ and \%yield. Optimized value was formulated into capsule dosage form and characterised by its different parameters as it shows the crystalline nature of the drug and convert into amorphous form and dissolution rate increases was found to be $99 \%$ by adding the surfactant also improves the solubility of poorly soluble drug. The application of experimental study was used for the optimization for the formulation that helps in reaching the optimum point with corrected value in the shortest time. 


\section{REFERENCES}

1. Brahmankar MD, Sunil JB. Biopharmaceutics and Pharmacokinetics A Treatise. 1995:19-20.

2. Bhirud Y, Phalak H, Advances in solid dispersion technology and its applications in the development of solid dosage forms. Journal of Drug Delivery and Therapeutics, 2016; 6(6):40-47. doi:10.22270/jddt.v6i6.1316

3. Khan A, Singh L, Various techniques of bioavailability enhancement: a review. Journal of Drug Delivery and Therapeutics, 2016; 6(3):34-41. doi:10.22270/jddt.v6i3.1228

4. Nagasamy V, R A, Saraswathi S, Padma Priya M, Khan N, Kathirulla N, Sruthi S, Dissolution enhancement of diacerein using water soluble carrier by solid dispersion technology. Journal of Drug Delivery and Therapeutics, 2017; 7(5):33-41. doi:10.22270/jddt.v7i5.1503

5. Mundhe A, Cocrystalization: an alternative approach for solid modification. Journal of Drug Delivery and Therapeutics, 2013; 3(4):166-172. doi:10.22270/jddt.v3i4.555

6. Galichet LY. Clarke's Analysis of Drugs and Poisons. $3^{\text {rd }}$ ed. Pharmaceutical Press September 2005.

7. Indian Pharmacopeia 2010; (3):2103-2104 and for Capsules; (2):721- 722

8. Kawamura Y. Carob Bean Gum. 2008 CTA: 1-6.

9. Patel M, Tekade Avinash, Gattani Surendra and Surana Sanjay. Solubility Enhancement of Lovastatin by Modified Locust Bean Gum Using Solid Dispersion. Techniques AAPS Pharm Sci Tech 2008; (9):1262-1269.
10. Rowe RC, Sheskey PJ, Owen SC. Handbook of Pharmaceutical Excipients. 5th ed. Washington: American Pharmaceutical Association 2005.

11. Patel HR, Patel RP, Patel MM. Poloxamers: A pharmaceutical excipients with therapeutic behaviours. J Pharm Tech Research 2009; (2):299-303.

12. Malik Karan, Arora Gurpreet, Singh Inderbir etal. Locust bean Gum as Superdisintegrant formulation and Evaluation of Nimesulide Orodispersible Tablets Polimery Medycynie 2011 17-28.

13. Verma S, Patel U, Patel R, Formulation and evaluation of ivermectin solid dispersion. Journal of Drug Delivery and Therapeutics, 2017; 7(7):15-17. doi:10.22270/jddt.v7i7.1572

14. Sharma U, Joshi A, Vyas N., Malviya S, Kharia A, Solubility enhancement of clopidogrel bisulfate by solid dispersion technique using carboxymethylcellulose sodium and xanthan gum. Journal of Drug Delivery and Therapeutics, 2017; 7(7):35-37. doi:10.22270/jddt.v7i7.1579

15. Pandya P, Gattani S, Jain P, Khirwal L, Surana S. Co-solvent Evaporation Method for Enhancement of Solubility and Dissolution Rate of Poorly Aqueous Soluble Drug Simvastatin: In vitro-In vivo Evaluation. AAPS Pharm SciTech 2008; 9(4):1247-1252.

16. Shende M, Fiske P, Fabrication and optimization of novel glipizide sustained release matrices for solubility and dissolution enhancement by solid dispersion through hydrophillic carriers. Journal of Drug Delivery and Therapeutics, 2017; 7(6):38-48. doi:10.22270/jddt.v7i6.1538 